\title{
Clinical and ultrasonographic evaluation of PPIUCD
}

\author{
Arihant Tater*, Swati Garg, Urvashi Sharma, Ashmita Jawa
}

Department of Obstetrics and Gynaecology, Mahatma Gandhi Medical College and Hospital, Jaipur, Rajasthan, India

Received: 12 February 2017

Revised: 18 March 2017

Accepted: 07 March 2017

\section{*Correspondence:}

Dr. Arihant Tater,

E-mail: dr.arihanttater@gmail.com

Copyright: (C) the author(s), publisher and licensee Medip Academy. This is an open-access article distributed under the terms of the Creative Commons Attribution Non-Commercial License, which permits unrestricted non-commercial use, distribution, and reproduction in any medium, provided the original work is properly cited.

\section{ABSTRACT}

Background: India is the second most populated country in the world. Effective contraception with low complication rates and high continuation rate in post-partum period can check population growth.

Methods: This is a prospective study carried out at Mahatma Gandhi Hospital after ethical committee approval. 100 patients giving the informed consent were taken in the study. PPIUCD inserted in patients and they were followed up at $48 \mathrm{hrs}, 6$ weeks and 12 weeks by clinical examination and USG.

Results: In this study, with PPIUCD insertion during LSCS, the expulsion and removal was observed in $4 \%$ and $14 \%$ whereas in cases with FTVD $8.33 \%$ expulsion and $12.5 \%$ removal were observed. $82 \%$ and $79.2 \%$ continued the use of PPIUCD in LSCS and FTVD respectively. The most common complain of the patients with PPIUCD were irritation because of thread. No case of pelvic infection or perforation was observed. There was no expulsion of PPIUCD when the distance of PPIUCD from fundus on USG was $<10 \mathrm{~mm}$.

Conclusion: PPIUCD have high continuation rates with low complication rate. Distance of PPIUCD from fundus on USG is not a good indicator for predicting expulsion of PPIUCD.

Keywords: FTVD, LSCS, PPIUCD, Post-partum

\section{INTRODUCTION}

India is the second most populated country in the world after China. According to the census 2011 the population of India on $1^{\text {st }}$ March 2011 was 1,210,193,422. In spite of the availability of wide range of contraception the unmet needs of contraception for family planning is estimated to be $12.8 \%$, the reason for the unmet needs are mainly lack of information, fear about the side effects of contraceptive methods and unsatisfactory services.

The recommended birth to birth interval in India is 36 months approximately $27 \%$ of birth in India occurs in less than 24 months after the previous birth and another $34 \%$ of birth occurs between 24 to 35 months. ${ }^{1}$ The main reason for the decreased interval of birth is lack of knowledge of contraception in post-partum period. The contraception used during this period should be safe and effective and focus on extended post-partum period.

Importance of post-partum family planning is as follows:

- Maternal health: Women becoming pregnant at short intervals faces problems like anemia, abortion, premature rupture of membranes and high maternal mortality

- Child health: short birth interval leads to increased risk of pre-term babies, Intra uterine growth retardation (IUGR), and increased death in neonatal period

- To fulfill the Unmet needs: $65 \%$ of the women in first year of delivery have unmet needs for family planning. Only $26 \%$ of the of the women in India are using any contraception in first year after delivery. ${ }^{2}$ 
Post-partum period, for the purpose of contraception can be divided as follows:

- Immediate post-partum period: Period starts from the delivery of placental tissue to the 48 hours. after delivery. In this period, the counselling about the exclusive breast feeding and the patient should be provided with provisions of appropriate family planning methods like PPIUCD, sterilization

- Early post-partum period: up to 7 days after the delivery

- $\quad$ Extended post-partum period: from the 6 weeks to 1 year after delivery. Birth spacing methods like IUCD and others can be provided as per medical eligibility criteria (MEC).

Intra uterine contraceptive device (IUCD) has been used since decades for spacing the pregnancy. The patients are highly motivated and receptive to family planning method during the post-partum period. As the IUCD can be inserted in immediate post-partum period this leads to the effective contraception from Day 1 of the delivery. This also reduces the multiple visits to the health care centre.

The objectives of the study are to access continuation rate, expulsion rate and removal rate in patient with PPIUCD, access the complication rates with PPIUCD and to evaluate whether USG is an appropriate investigation for the follow up of the PPIUCD.

\section{METHODS}

It is a prospective observational study, carried out at department of obstetrics and gynecology, Mahatma Gandhi medical college and hospital, Jaipur after taking the clearance from Institutional Ethical Committee. The patients delivered, either vaginally or by LSCS, in the department of obstetrics and gynecology, giving informed consent for the insertion of PPIUCD were studied. 190 patients were counseled, 100 cases who gave the informed consent for insertion of PPIUCD were studied. Among those 50 were after normal vaginal delivery and other 50 with lower segment cesarean section. There were 2 cases post FTVD who lost to follow up. The study is carried out from March 2016 to September 2016.

\section{Inclusion criteria}

- $\quad$ Patient giving informed consent.

- The cu-T 380 A will be inserted just after delivery of placenta, intra cesarean, and within 48 hours of normal vaginal delivery.

\section{Exclusion criteria}

- $\quad$ History of AUB.
- History of sexually transmitted disease (STD) and pelvic inflammatory disease (PID).

- Postpartum hemorrhage, extensive genital trauma during vaginal delivery and LSCS.

- Benign and malignant trophoblastic disease.

- Distorted uterine cavity

$\mathrm{Cu}-\mathrm{T} 380 \mathrm{~A}$ is approved for the post-partum intra uterine contraceptive device. The cu-T $380 \mathrm{~A}$ is very effective. There are only .6 to. 8 pregnancies per 100 women in first year of use. ${ }^{3}$ It can be used for the 10 years continuously or for whatever time period the women wants up to 10 years. PPIUCD inhibits the sperm migration, sperm survival, ovum transport and causes inflammatory reactions in the endometrium due to sterile foreign body and copper.

Consent of the patient is taken in written on pre-designed consent form in both English and Hindi including potential risks.

\section{Timing of insertion of PPIUCD}

- Post placental: the PPIUCD is inserted within 10 minutes after the delivery of the placenta. Can be inserted manually or by instruments.

- Intra cesarean: inserted after delivery of placenta, inserted through the uterine incision manually and the incision is closed. $\mathrm{Cu}-\mathrm{T}$ thread should not come in stichline.

- Within 48 hours of delivery

\section{Method of insertion of PPIUCD}

After taking informed consent, the patient and her records were examined to ensure that the patient is fit with respect to inclusion and exclusion criteria. Inspection of perineum, vaginal wall to exclude any tear or lacerations. If present and not bleeding heavily, insert IUCD and then repair. If there is excess bleeding from tear then repair first.

Visualization of cervix with Sim's speculum and grasp anterior lip of cervix with sponge holding forcep after cleaning the cervix with povidine iodine. The IUCD is taken in sponge holding forcep or Kelly's forcep byno touch technique. Gentle traction is given to the anterior lip of the cervix and the PPIUCD is inserted.

Abdominally uterus is pushed superiorly (upwards) thus straightening the angle between the vagina and the uterus. So, that the instrument can easily move and reach uterine fundus. The Kelly's forceps are advanced to the fundus and the resistance felt, this is confirmed by feeling thrust on the hand (per abdomen) on fundus. The PPIUCD is released and the instrument is swept to the right and withdrawn slowly keeping instrument open. The PPIUCD can be inserted manually at the fundus in post-placental and in LSCS cases. 
Provide information of PPIUCD on discharge card, inform about the warning sign and side effects and to visit hospital in case of any sign, inform about the follow up.

Follow up: The patient is first evaluated after 48 hrs. of insertion. Patient was asked for satisfaction with this method. Pelvic examination was done to rule out STD, PID, and expulsion of IUCD. The warning signs and expulsion of PPIUCD were explained again. If PPIUCD is expelled then offer other contraceptive methods. USG was done to measure the distance of the horizontal arm of
cu-T380A with the fundus, to know that the IUCD is properly placed or not. The same follow up steps were done at 6 weeks and 12 weeks of delivery.

\section{RESULTS}

In this study, the 50 cases of LSCS the expulsion and removal was observed in $4 \%$ and $14 \%$ of cases respectively, whereas in cases with FTVD $8.33 \%$ expulsion and $12.5 \%$ removal were observed. $82 \%$ and $79.2 \%$ continued the use of PPIUCD in LSCS and FTVD respectively (Table 1$)$.

Table 1: Comparison of expulsion rate of PPIUCD after FTVD and LSCS.

\begin{tabular}{|lllll|}
\hline Mode of delivery & Total Cases followed & Expulsion & Removed & Continued \\
\hline LSCS & 50 & $2(4 \%)$ & $7(14 \%)$ & $41(82 \%)$ \\
\hline FTVD & 48 & $4(8.33 \%)$ & $6(12.5 \%)$ & $38(79.2 \%)$ \\
\hline Total & $\mathbf{9 8}$ & $\mathbf{6 ( 6 . 1 \% )}$ & $\mathbf{1 3 ( 1 3 . 3 \% )}$ & $\mathbf{7 9 ( 8 0 . 6 \% )}$ \\
\hline
\end{tabular}

Table 2: Continuation and Removal rates for the complications at 6 weeks.

\begin{tabular}{|llllll|}
$\begin{array}{l}\text { Complications } \\
\text { at } 6 \text { weeks }\end{array}$ & $\begin{array}{l}\text { No. of } \\
\text { patients }\end{array}$ & $\begin{array}{l}\text { Continuation } \\
\text { at } 6 \text { weeks }\end{array}$ & $\begin{array}{l}\text { Removal } \\
\text { at } 6 \text { weeks }\end{array}$ & $\begin{array}{l}\text { Percentage } \\
\text { Removed }\end{array}$ & $\begin{array}{l}\text { Contribution to } \\
\text { complications at 6 weeks }\end{array}$ \\
\hline Thread Felt & 52 & 52 & 0 & 0 & $53 \%$ \\
\hline Pain abdomen & 12 & 9 & 3 & 25 & $12 \%$ \\
\hline Bleeding & 5 & 5 & 0 & 0 & $5 \%$ \\
\hline Pelvic infection & 0 & 0 & 0 & 0 & 0 \\
\hline Perforation & 0 & 0 & 0 & 0 & 0 \\
\hline No Complain & 29 & 25 (+4expulsion) & 0 & 0 & $30 \%$ \\
\hline
\end{tabular}

The major complains of the patients with PPIUCD at 6 weeks were irritation because of thread $53 \%$. Pain abdomen is the second major complain (12\%). Bleeding $\mathrm{PV}$ is observed in 5 cases. No complain was observed in $30 \%$ of the patients.

No case of pelvic infection or perforation was observed. Removal rate at 6 weeks is maximum with pain abdomen that is $25 \%$ of the patients who complained pain abdomen. Rest in all complains and complications the cases wished to continue the PPIUCD (Table 2).

The patient with no complains increases from $30 \%$ at 6 weeks to $74 \%$ at 12 wks. The major complain is again thread felt in $12 \%$ of the cases. Pain abdomen was there in $9 \%$ and bleeding PV was in $5 \%$ of the cases. $100 \%$ of the patient with bleeding PV gets the PPIUCD removed and $62 \%$ of the patient with pain abdomen got the PPIUCD removed (Table 3).

Table 3: Continuation and removal rates for the complications at 12 weeks.

\begin{tabular}{|llllll|}
\hline $\begin{array}{l}\text { Complications } \\
\text { at 12 weeks }\end{array}$ & $\begin{array}{l}\text { No. of } \\
\text { patients }\end{array}$ & $\begin{array}{l}\text { Continuation } \\
\text { at 12 weeks }\end{array}$ & $\begin{array}{l}\text { Removal } \\
\text { at 12 weeks }\end{array}$ & $\begin{array}{l}\text { Percentage } \\
\text { Removed }\end{array}$ & $\begin{array}{l}\text { Contribution } \\
\text { to Complications at 12 weeks }\end{array}$ \\
\hline Thread Felt & 11 & 11 & 0 & 0 & 12 \\
\hline Pain abdomen & 8 & 3 & 5 & 62 & 9 \\
\hline Bleeding & 5 & 0 & 5 & 100 & 5 \\
\hline Pelvic infection & 0 & 0 & 0 & 0 & 0 \\
\hline Perforation & 0 & 0 & 0 & 0 & 74 \\
\hline No Complain & 67 & $65(+2$ expulsion) & 0 & 0 & 0 \\
\hline
\end{tabular}


There was no expulsion of PPIUCD at 12 wks when the distance of PPIUCD was $<10 \mathrm{~mm}$ at $6 \mathrm{wks}$ of insertion. There is no relation between the expulsion and the distance of PPIUCD from fundus when the distance is $10-20 \mathrm{~mm}$ and more than $20 \mathrm{~mm}$ at 6 wks. In both categories the expulsion was in $3 \%$ of the cases Table 5 .

Table 4: Relation of USG guided measurement of distance between fundus and PPIUCD at 48 hrs. with expulsion at 6 weeks.

\begin{tabular}{|llll|}
\hline Distance & No. of Patients & Expulsion & Percent \\
\hline$<10 \mathrm{~mm}$. & 38 & 0 & 0 \\
\hline $10-20 \mathrm{~mm}$. & 31 & 2 & 6.5 \\
\hline$>20 \mathrm{~mm}$. & 31 & 2 & 6.5 \\
\hline
\end{tabular}

Table 5: Relation of USG guided measurement of distance between fundus and PPIUCD at 6 wks with expulsion at 12 weeks.

\begin{tabular}{|clll|}
\hline Distance & No. of Patients & Expulsion & Percent \\
\hline$<10 \mathrm{~mm}$. & 30 & 0 & 0 \\
\hline $10-20 \mathrm{~mm}$. & 33 & 1 & 3 \\
\hline$>20 \mathrm{~mm}$. & 31 & 1 & 3 \\
\hline
\end{tabular}

\section{DISCUSSION}

In the present study, the major complains of the patients with PPIUCD at 6 weeks were irritation because of thread 53\%. Another study also concluded that the string problem (363 cases) is most common complication. ${ }^{4}$ in present study, Pain abdomen is the second major complain (12\%). Bleeding PV is observed in $5 \%$ cases. Removal rate at 6 weeks is maximum with pain abdomen that is $25 \%$ of the patients who complained pain abdomen. Rest in all complains and complications the cases wished to continue the PPIUCD. At 12 weeks, the patient with no complains increases from $30 \%$ at 6 weeks to $74 \%$ at 12 wks. The major complain is again thread felt in $12 \%$ of the cases. Pain abdomen was there in $9 \%$ and bleeding PV was in $5 \%$ of the cases. Other study also reported pain abdomen in $8.9 \%$ and menstrual complains in $5.5 \%$ cases. ${ }^{5}$ The incidence of bleeding in different studies were $4.3 \%{ }^{6}, 27.2 \%^{7}$ and $23.5 \%$, the removal due to pain and bleeding range from 6 to $8 \% .^{8-10}$

No case of pelvic infection or perforation was observed at both 6 weeks and 12 wks. The result is consistent with P. Malathi et al, there also author had no case of perforation and pelvic infection. ${ }^{4}$ There is no case of uterine perforation in the study done at Rohtak. ${ }^{11}$ Another trial did not find any instance of infection due to PPIUCD. ${ }^{12} \mathrm{~A}$ study in Paraguay reported infection rate of $0.1 \% .^{13}$ Our study is inconsistent with a study done in Jhansi which had higher pelvic infection rates of $4.3 \%$ and with Kumar et al. where the pelvic infections were $5 \%$. A multicentric study in India reported overall infection of $4.5 \%$ amongst PPIUCD insertion. ${ }^{5,14,15}$ Some studies like our study had not found any case of pelvic infections after PPIUCD insertion. ${ }^{7,10,12}$

There was no expulsion of PPIUCD at 6 weeks and 12 weeks, when the distance of PPIUCD was $<10 \mathrm{~mm}$ from fundus at 48 hours and 6 wks. of insertion respectively. This study is consistent with Neha Goyal et al in which there is no expulsion in cases of distance $<10 \mathrm{~mm} .{ }^{16} \mathrm{In}$ this study there was no relation between the expulsion and the distance of PPIUCD from fundus when the distance is 10-20 mm and more than $20 \mathrm{~mm}$. At $6 \mathrm{wks}$, in both categories the expulsion was in $6.5 \%$ of the cases and at 12 weeks in both groups it was $3 \%$. So, this conclude that there is no expulsion when distance is $<10$ $\mathrm{mm}$ but when the distance increases, we cannot predict the expulsion of PPIUCD on the basis of distance from the fundus and the USG is not appropriate diagnosis in predicting the expulsion of PPIUCD. This is contrary Neha $G$ et al as they compared the cases on the basis of $<10 \mathrm{~mm}$ and more than $10 \mathrm{~mm}$ and concluded that the USG can predict the expulsion. ${ }^{16}$

The expulsion is more in the post vaginal delivery patients, the finding is consistent with Reetu Hooda et al. ${ }^{11}$ In the present study, the Expulsion with the LSCS was $4 \%$ which is similar to Celen et al $5.3 \% .^{10}$ in the present study, the total Expulsion rate is $6.1 \%$, removal rate is $13.3 \%$ and the continuation rate is $80.6 \%$. In other studies, where similar procedures and trained providers were there the similar rate of Expulsion were observed like $5.23 \%$ in Kittur and Kabadi et al, $5.3 \%$ in Reetu Hooda et. ${ }^{11}$ The removal rates are higher than other recent studies which range from 3 to $8 \%$. $7,9,10,15,16$ Still in this study continuation rates are approx $81 \%$ and thus we are providing contraceptive method to the big population thus decreasing the unmet needs of contraception.

\section{ACKNOWLEDGEMENTS}

Author would like to thank all mighty God who blessed him to come till here. Author would like to thanks patients. Author extremly grateful to his guide Dr. Swati Garg for her emence support and guidance during the study. Author thankful to his parents, his betterhalf, my colleagues and to all those who were directly or indirectly related to this study and supported his during the study.

Funding: No funding sources

Conflict of interest: None declared

Ethical approval: The study was approved by the Institutional Ethics Committee

\section{REFERENCES}

1. Post-partum IUCD reference manual. New Delhi: Family Planning Division, Ministry of Health and Family Welfare, Government of India; 2010.

2. Borda M. Family Planning Needs during the Extended Postpartum Period in India. Access Family Planning Initiative Brief, 2009. 
3. Garuda L, Kambham S, Neelohita. Clinical outcome of PPIUCD (Copper-380A)-intracaesarean insertion Indian J Obstet Gynaecol Res. 2015;2(4):218-26.

4. Malathi P, Patalay K. Intra cesarean-intra uterine contraceptive device 380 a insertion: 3 years experience at a tertiary care center. IAIM. 2016;3(8):241-7.

5. Kumar S, Sethi R, Balasubramaniam S, Charurat E. Women's experience with postpartum intrauterine contraceptive device use in India. Reproduc Health 2014,11:32.

6. Gupta A, Verma A, Chauhan J. Evaluation of PPIUCD versus interval IUCD (380A) insertion in a teaching hospital of Western U.P. Int J Reproduc Contracep Obstet Gynecol. 2013;2:204-8.

7. Shukla M, Qureshi, S Chandravati, Post-placental intrauterine device insertion. A 5 years' experience at a tertiary case centre in north India. Indian $\mathbf{J}$ med Res. 2012;136(3):432-5.

8. Sujnanendra M. Evaluation of safety, efficacy, and expulsion of post-placental and intra-cesarean insertion of intrauterine contraceptive devices (PPIUCD). J Obstet Gynecol India. 2014;64(5):337-43.

9. Kittur S International Journal of Reproduction, Contraception, Obstetrics and Gynecology. Int J Reprod Contracept Obstet Gynecol. 2012;1(1):26-32.
10. Şevki Çelen S, Ayhan Sucak, Yasemin Yıldız, Nuri Danışman. Immediate postplacental insertion of an intrauterine contraceptive device during cesarean section. Contraception. 2011;84:240-3.

11. Hooda R, Mann S, Nanda S, Gupta A, More H, Bhutani J. Immediate Postpartum Intrauterine Contraceptive Device Insertions in Caesarean and Vaginal Deliveries: A Comparative Study of FollowUp Outcomes. Int J Reprod Med. 2016;2016.

12. Tatum HJ, Beltran RS, Ramos R, Van Kets H, Sivin I, Schmidt FH, Ortho-McNeil I. Immediate postplacental insertion of GYNE-T 380 and GYNET 380 postpartum intrauterine contraceptive devices: randomized study. Am J Obstet Gynecol. 1996;175(5):1231-5.

13. Araujo VB, Ortiz L, Smith J: Postpartum IUD in Paraguay: a case series of 3000 cases. Contracep. 2012,86:173-86

14. Gautam R, Arya KN, Kharakwal S, Singh S, Trivedi M. Overview of immediate PPIUCD application in Bundelkhand region. J Evol Med Dental Sci. 2014;3(36):9518-26.

15. Maternal and Child Health Integrated Program and PPFP activities, WHO Report.

16. Goyal N. Post placental intrauterine contraceptive device-an ultrasound guided follow up study. Indian J App Res. 2015;5(6):454:6.

Cite this article as: Tater A, Garg S, Sharma U, Jawa A. Clinical and ultrasonographic evaluation of PPIUCD. Int J Reprod Contracept Obstet Gynecol 2017;6:1578-82. 